C.А. БАРАНОВ, К.М.Н., В.М. НЕЧАЕВ, К.М.Н.

Первый Московский государственный медицинский университет им. И.М. Сеченова Минздрава России

\title{
НЕЙРОПАТИЧЕСКАЯ БОЛЬ
}

\section{АБДОМИНАЛЬНОЙ ЛОКАЛИЗАЦИИ}

\begin{abstract}
Боль в животе разнородна по своему происхождению (висцеральная, отраженная, центрально-опосредованная, сенестопатии, нейропатическая). Нейропатическая абдоминальная боль мало знакома терапевтам. Она имеет свои клинические особенности: гипералгезия (аллодиния), гигромания, сочетание с вегетативной дисфункцией. На передней брюшной стенке определяются болевые триггерные точки и положительный симптом Карнетта. Устранение нейропатической абдоминальной боли достигается посредством курсового применения комбинации лекарственных средств (местные анестетики, неопиоидные анальгетики, антиконвульсанты, антидепрессанты), а при недостаточной их эффективности показано хирургическое вмешательство (удаление терминальных отделов межреберных нервов в области прямой мышцы живота). Эффективность подобного комплексного лечения достигает $73 \%$.
\end{abstract}

Ключевые слова: нейропатическая абдоминальная боль, комплексный регионарный болевой синдром, аллодиния.

\section{S.A. BARANOV, PhD in Medicine, V.M. NECHAEV, PhD in Medicine}

Sechenov First Moscow state medical university Ministry of Healthcare of the Russian Federation NEUROPATHIC ABDOMINAL PAIN

The abdominal pain is diverse on the parentage (visceral, reflected, central-mediated, senesthopathias, neuropathic). The neuropathic abdominal pain is a little familiar to therapists. It has the clinical features: an allodynia (hyperalgesia), a hygromania, a combination to vegetative dysfunction. On a forward abdominal wall painful trigger points and a positive Carnett's symptom are defined. Elimination of a neuropathic abdominal pain is reached by means of course application of a combination of medical products (local anaesthetics, non-opioid analgetics, anticonvulsants, antidepressants), and at their insufficient efficiency the surgical intervention (excision of terminal departments of intercostal nerves in the field of a direct muscle of a stomach) is shown. Efficiency of similar complex treatment reaches $\mathbf{7 3 \%}$.

Keywords: neuropathic abdominal pain, complex regional pain syndrome, allodynia.

бдоминальная боль есть один из ключевых симптомов в гастроэнтерологии, анализ которого в большинстве случаев позволяет не только сформулировать своевременный правильный диагноз, но и оценить результаты лечения.

По своему происхождению боль в животе неоднородна. У большинства пациентов болевые ощущения имеют висцеральное происхождение, то есть обусловлены непосредственным поражением органов брюшной полости. Клинические признаки висцеральных болей достаточно характерны и хорошо известны: 1) их эпицентр в целом соответствует проекции пораженного органа; 2) боль возникает или усиливается после нагрузки на пораженный орган (прием пищи) и уменьшается «в покое» (голодание ${ }^{1}$, дефекация); 3) боль иррадиирует в зоны Захарьина - Геда для пораженного органа (правое плечо и правая лопатка при заболеваниях желчного пузыря); 4) сочетается с другой гастроэнтерологической симптоматикой (тошнота, борборигмы, изжога и пр.); 5) вышеописанные признаки качественно статичны, то есть наблюдаются практически без качественных изменений до наступления ремиссии; 6) прием специализированных гастроэнтерологических препаратов (антисекреторные средства, миотропные спазмолитики, холинолитики, антациды) оказывает на висцеральную боль отчетливый положительный клинический эффект. Следует подчеркнуть, что эти 6 клинических особенностей присущи в первую очередь висцеральным болям неонкологического генеза (non-cancer pain).

\footnotetext{
${ }^{1}$ Исключение составляет язвенная гастродуоденальная боль, появляющаяся на голодный
} желудок и уменьшающаяся после приема пищи.
Отраженные боли в животе наблюдаются примерно у $1 \%$ населения и имеют своим субстратом заболевания грудной полости и позвоночника. Так, например, при инфаркте миокарда нижнедиафрагмальной локализации могут наблюдаться боли в эпигастрии. Для идентификации абдоминальных болей как отраженных необходимо помнить, что, во-первых, они лишены признаков висцеральных болей, и, во-вторых, у таких пациентов всегда выявляется симптоматика причинного заболевания. В случае инфаркта миокарда это будут одышка, снижение артериального давления, характерные изменения на ЭКГ и в анализах крови.

Висцеральные и отраженные боли в животе по своему патогенезу относятся к разряду ноцицептивных, то есть возникающих при воздействии повреждающего фактора на болевые рецепторы.

Функциональные абдоминальные боли встречаются у 0,5-2,0\% населения. К настоящему моменту их патогенез изучен недостаточно. В соответствии с Римскими диагностическими критериями IV пересмотра (2016) они входят в группу функциональных гастроинтестинальных расстройств (ФГИР) под литерой Н2 и определяются как нарушение взаимодействия «кишка - головной мозг» (disorders of gut - brain interaction). Непременным условием положительного диагноза синдрома функциональной абдоминальной боли (СФАБ) является отсутствие явной его причины, а именно каких-либо «органических заболеваний и структурных нарушений органов брюшной полости», а также психических заболеваний. Авторы Римских критериев IV осознают всю неоднозначность термина «функциональный» и рекомендуют по возможности избегать его, частично построив свою классификацию по принципу 
органопатологии. Например, термин СФАБ заменен ими на «центрально-опосредованную абдоминальную боль» (литера D), к которой они причисляют и боли в животе с известной этиологией («опиоид-индуцированная гастроинтестинальная гипералгезия», литера D2) [1-3]. Таким образом, центрально-опосредованная абдоминальная боль представляет собой один из вариантов психогении.

Другой разновидностью психогении являются сенестопатии, то есть тягостные, неприятные ощущения (в том числе болевые), локализуемые на поверхности тела или во внутренних органах, лишенные предметности (чем отличаются от висцеральных галлюцинаций $\left.{ }^{2}\right)$ и возникающие в отсутствие объективного патологического процесса в месте их локализации. Сенестопатии входят в структуру ипохондрического бреда, депрессивного синдрома, синдрома психического автоматизма. Они характеризуются появлением необычных ощущений у больного («печень чешется»), имеют свое индивидуальное течение с частой сменой локализации и характера. Сенестопатические боли могут локализоваться и в животе. Они также вычурны и необычны. Подобные боли, как правило, характеризуются выраженной эмоциональной окраской («невыносимые, дикие, рвущие, животные, сумасшедшие»). Некоторым пациентам кажется, что обычная физическая боль переносится гораздо легче, чем сами сенестопатии. Поскольку в их патогенезе участвуют различные психические функции человека, они далеко выступают за рамки обычных нарушений чувствительности [4].

Висцеральные, отраженные и центрально-опосредованные боли в животе включены в круг интересов врачейинтернистов (гастроэнтерологов). Сенестопатии - прерогатива психиатров. Интерпретируя весь спектр абдоминальных болевых ощущений, врачи данных специализаций стараются не выходить за пределы своей компетенции, что вполне естественно, но не всегда оправданно, поскольку существует еще один тип болей в животе. Это нейропатические боли. Их происхождение вызвано не раздражением болевых рецепторов, а непосредственным органическим поражением нервной системы (периферические нервы, корешки, сплетения, задние рога и столбы спинного мозга, ствол, таламус, большие полушария головного мозга). При этом в патологический процесс вовлекаются проводящие пути (спиноталамический, спиноретикулярный, спиномезэнцефалический и спиноцервикальный). Патофизиологической основой нейропатической боли является нарушение генерации потенциалов в поврежденном нерве и тормозного контроля возбудимости ноцицептивных нейронов в центральных структурах мозга. Одним из основных механизмов невропатической боли служит повышение возбудимости мембран нервных волокон [5].

В зависимости от локализации различают периферическую и центральную нейропатическую боль. Первая своим морфологическим субстратом имеет периферическую полинейропатию (диабетическую, алкогольную, демиелинизирующую), компрессию корешка или травму нерва. Примером периферической нейропатической боли явля-

\footnotetext{
2 Висцеральные галлюцинации - ощущение наличия во внутренних органах человека посторон-
} них предметов, чаще живых существ: змей, лягушек, гвоздей, радиопередатчиков и так далее. ется так называемый синдром ущемления передних кожных нервов (anterior cutaneous nerve entrapment syndrome, ACNES). Он развивается в послеоперационном периоде вследствие «ущемления» нервных окончаний 7-12 грудных межреберных нервов в шовной области брюшных мышц и проявляется выраженной локальной болью в животе. Данный синдром редко диагностируется, хотя встречается у 1 из 2000 пациентов [6]. Центральная нейропатическая боль развивается при поражении спинного мозга, ствола мозга, зрительного бугра и коры больших полушарий (компрессионная, сосудистая, демиелинизирующая или ВИЧ-обусловленная миелопатия, опухоль, фуникулярный миелоз, боль при болезни Паркинсона) и также может иметь абдоминальную локализацию.

Для обозначения нейропатической боли ранее широко использовались абстрактные термины «каузалгия» и «симпаталгия» («симпатические поддерживаемая боль»). Учитывая сложносоставной характер этой группы болевых ощущений, с 1994 г. введено понятие «комплексный регионарный болевой синдром» (КРБС), объединяющий чувствительные, двигательные и вегетативно-трофические расстройства. Оно используется главным образом в неврологии для обозначения патологических состояний опорно-двигательного аппарата (синдромы Зудека и Стейнброккера) [7] и практически не применяется к случаям нейропатической абдоминальной локализации, что вряд ли оправданно.

Клинические особенности нейропатической боли достаточно характерны, что в большинстве случаев делает возможной правильную ее идентификацию уже на этапах расспроса и физикального обследования больного. Различают два компонента нейропатической боли - спонтанная и гипералгезия. В свою очередь, спонтанная боль подразделяется на симпатически независимую и симпатически поддерживаемую. Симпатически независимые болевые ощущения развиваются вследствие повреждения соматического нерва, имеют характер прострелов и регрессируют после его блокады местным анестетиком. Симпатически поддерживаемая боль обычно носит жгучий характер и сочетается с разнообразными проявлениями дисфункции автономной нервной системы (локальные нарушения кровотока, терморегуляции, потоотделения и мышечного тонуса в виде тремора или судорожных подергиваний). Эта боль уменьшается после симпатической блокады.

Вторым компонентом нейропатической боли является гипералгезия, наблюдаемая практически у всех больных и в зависимости от локализации подразделяемая на первичную и вторичную. Первичная гипералгезия возникает непосредственно в поврежденном участке вследствие сенсибилизации периферических болевых рецепторов биологически активными веществами (нейроактивные пептиды, кинины, простагландины и лейкотриены). Вторичная гипералгезия далеко выходит за зону тканевого повреждения или область иннервации пораженного нерва. Ее происхождение связано со вторичной сенсибилизацией задних рогов спинного мозга и интактных сенсорных волокон. Выделение первичной и вторичной гипералгезий имеет, скорее, академический интерес, поскольку идентифицировать пораженный нерв удается далеко не всегда. 
Разновидностью гипералгезии является аллодиния, то есть локальные болевые ощущения, возникающие под воздействием раздражителей, обычно не вызывающих боль. Выделяют механическую, динамическую и температурную аллодинии. Аллодинию не следует отождествлять с симптомом рубашки, описанным А.П. Воскресенским при остром аппендиците и относящимся к группе висцеральных болей. Означенный симптом воспроизводится следующим образом: своей левой рукой врач натягивает рубашку больного за ее нижний край. Больной делает вдох, а в это время врач кончиками пальцев осуществляет легкое скользящее движение сверху живота вниз по направлению к правой подвздошной области. В момент окончания скольжения в данной области живота появляется или резко усиливается болезненность.

Как правило, нейропатическая боль сопровождается дисфункцией вегетативной (автономной) нервной системы. Так, например, у лиц с синдромом ущемления передних кожных нервов нередко наблюдаются тошнота, флатуленция, метеоризм, потеря аппетита со снижением массы тела и нарушения дефекации. Это дает основание вести речь о феномене «висцерализации» нейропатической боли, который в ряде случаев затрудняет дифференциальную диагностику между ней и висцеральной болью.

У некоторых пациентов с выраженными нейропатическими болями наблюдается гигромания (симптом «мокрой тряпки»). Такие больные беспрестанно смачивают свое тело водой, предъявляют жалобы на сильную жажду и сухость во рту, что сопровождается отвращением к виду сухих предметов или даже мыслям о них. Гигромания развивается исключительно у мужчин. Ее патогенез неизвестен [6-10].

Как правило, при физикальном обследовании на передней брюшной стенке удается обнаружить одну или несколько болевых точек, боль в которых усиливается при напряжении мышц брюшного пресса (симптом Карнетта)ㄱ. Нередко ограниченный участок максимальной боли покрыт более крупной областью измененной кожной чувствительности с вышеописанными соматосенсорными нарушениями. Сдавление кожи между большим и указательным пальцами чрезвычайно болезненно по сравнению с противоположной интактной стороной. Инъекция местного анестетика в триггерную точку брюшной стенки приводит к уменьшению боли [6]. Будапештские диагностические критерии комплексного регионарного болевого синдрома [7] разработаны для нужд невропатологов и в ситуациях нейропатической боли абдоминальной локализации имеют ограниченное применение. Следует добавить, что в определенном проценте случаев нейропатические боли в животе сочетаются с висцеральными, как бы «маскируясь» ими. Это порождает дополнительные дифференциально-диагностические трудности, преодолеть которые помогает следующее правило: если на фоне адекватного лечения узкоспециализированными гастроэнтерологическими препаратами должного клинического эффекта достичь не удается, следует предположить возможность наличия нейропатической

Висцеральные галлюцинации - ощущение наличия во внутренних органах человека посторонних предметов, чаще живых существ: змей, лягушек, гвоздей, радиопередатчиков и т.д. абдоминальной боли. Такие больные должны быть проконсультированы квалифицированными невропатологами.

Лечение висцеральных и нейропатических болей основывается на диагностике и последующей терапии вызывающего их заболевания (язвенная болезнь, хронический калькулезный холецистит, острая пневмония и пр.). Современные схемы лечения нейропатической боли, включая и абдоминальную, как правило, включают минимум две группы препаратов. В качестве дебютной терапии используются инъекции местных анестетиков (2\%-ный раствор лидокаина) в триггерные точки в комбинации с ненаркотическими анальгетиками. Одними из наиболее эффективных неопиоидных анальгетиков являются флупиртина малеат (нолодатак, катадолон) в дозе 200 мг/сут, а также ацеклофенак (аленталь) в дозе 200 мг/сут. При отсутствии явного положительного результата спустя 5-7 дней целесообразно подключение антиконвульсантов - габапентина (тебантина) по 300 мг на ночь с увеличением дозы на 300 мг в неделю до уровня 900-1200 мг/сут или прегабалина (лирика) по 150 мг/сут с последующим возможным увеличением дозы до 300-450 мг/сут. Продолжительность лечения антиконвульсантами составляет в среднем 8-12 недель. Отчетливым анальгетическим эффектом обладают также антидепрессанты, в частности амитриптилин (триптизол) в дозе 25-50 мг/сут курсом не менее 8 недель. Сочетание противосудорожных препаратов с антидепрессантами неоправданно ввиду отрицательного их взаимодействия.

Пациентам с синдромом ущемления передних кожных нервов, которые не отвечают на фармакотерапию, показано хирургическое вмешательство - удаление терминальных отделов межреберных нервов в области прямой мышцы живота («передняя нейрэктомия»). При этом стойкий положительный эффект наблюдается в 73\% случаев, что подтверждено проспективным двойным слепым хирургическим тестом [6, 7, 11, 12].

\section{ЛИТЕРАТУРА}

1. Drossman D. A. Functional gastrointestinal disorders: history, pathophysiology, clinical features, and Rome IV. Gastroenterol, 2016, 150(6): 1262-1279.

2. Шептулин А.А. Синдром функциональной абдоминальной боли. Кримський терапевтичний журнал, 2013, 2: 9-14

3. Clouse RE, Mayer EA, Aziz Q et al. Functional abdominal pain syndrome. Gastroenterol, 2006, 130: 1492-1497.

4. Эглитис Р.И. Сенестопатии: Зинатне, Рига. 1977: 1-5.

5. Dosenovic S, Jelicic Kadic A, Miljanovic M, Biocic M, Boric K, Cavar M, Markovina N, Vucic K, Puljak L. Interventions for Neuropathic Pain: An Overview of Systematic Reviews. , 2017, 125(2): 643-652.

6. Roumen RMH, Vening W, Wouda R, Scheltinga MM. Acute Appendicitis, Somatosensory Disturbances («Head Zones»), and the Differential Diagnosis of Anterior Cutaneous Nerve Entrapment Syndrome (ACNES). J Gastrointest Surg, 2017, 21(6): 1055-1061.

7. Корячкин В.А. Комплексный регионарный болевой синдром: посо бие для врачей. СПб.: РНИИТО, 2014. 32 с.

8. Visnjevac O, Costandi S, Patel BA, Azer G, Agarwal P, Bolash R, Mekhail NA. A Comprehensive Outcome-Specific Review of the Use of Spinal Cord Stimulation for Complex Regional Pain Syndrome. Pain Pract, 2017, 17(4): 533-545.

9. Hernández-Porras BC, Plancarte-Sánchez R, Alarcón-Barrios S, Sámano-García M. Complex regional pain syndrome: A review. Cir Cir, 2017, 85(4): 366-374.

10. Новиков А.В., Яхно Н.Н. Комплексный регионарный болевой синдром как вариант хронической нейропатической боли. РМЖ, 2001, 25: 1152

11. Баранцевич Е.Р., Живолупов С.А., Самарцев И.Н. Приоритетные направления формировании болезнь-модифицирующей терапии хронических болевых синдромов в неврологии. РМЖ, Неврология, 2017, 9: 642-647.

12. Аверченкова А.А., Рачин А.П. Лечение скелетно-мышечной боли: от теории к практике. РМЖ, Неврология, 2017, 9: 681-686. 